\title{
Malaria in children in Birmingham in the 1970s
}

\author{
D. P. ADDY \\ F.R.C.P., D.C.H.
}

\author{
P. M. MATHEW \\ M.D., M.R.C.P.
}

Department of Paediatrics, Dudley Road Hospital, Birmingham B18 7QH

\begin{abstract}
Summary
Thirty-two children with malaria were admitted to Dudley Road Hospital, Birmingham, in the 1970s. None was admitted before 1974 and there was a rapid increase after that. All the infections were due to Plasmodium vivax and occurred in children of Asian immigrant families who had been born in or had visited India or Pakistan apart from one infant born in England who acquired the disease transplacentally. All presented within 12 months of entering or reentering the United Kingdom. The clinical features of the 32 patients have been analysed and it is suggested that more effort should be made to educate travellers about the need for anti-malarial chemoprophylaxis and the necessity to continue it for one month after return.
\end{abstract}

\section{Introduction}

The second half of the last decade has seen a sharp increase in the number of cases of malaria in Birmingham (Fig. 1). This increase has also been seen in other centres as well as in national figures (Ellis et al., 1979; Malaria Reference Laboratory, personal communication, 1980; Rutter, 1977; Robinson and Eykyn, 1977; Thompson et al., 1979; Warwick, Swimer and Britt, 1979). This trend has been seen in children and in adults.

The authors present observations on 32 cases of childhood malaria seen in their hospital in the 6 years 1974-79. They also report in detail one case of transplacentally acquired malarial infection.

\section{Patients and methods}

The case notes of all 32 children aged 16 years or less admitted to Dudley Road Hospital, Birmingham, with malaria during the years 1970-79 were examined. No cases recorded before 1974 were found. All laboratory examinations were performed in the Haematology Laboratory, Dudley Road Hospital.

\section{Results}

There were 20 boys and 12 girls. Younger children predominated; 20 were aged 6 years or less and 27 were 10 years old or less. One child had congenital malaria and is described further below.

The families of 20 of the children had emigrated from India and the remaining 12 were from Pakistan. Twenty-one of the children were born in Great Britain, 4 in India and 7 in Pakistan. Eight children were recent immigrants, 3 of these were from India and 5 from Pakistan. Twenty-three had recently visited the Indian sub-continent; 16 to India and 6 to Pakistan (one-not known which of the 2 countries). One infant acquired the disease transplacentally.

All had left the endemic area within 12 months before diagnosis, but 12 had returned more than 6 months previously. Four had symptoms of less than 24 hours' duration and 21 had become symptomatic within one week of admission. Six had had symptoms

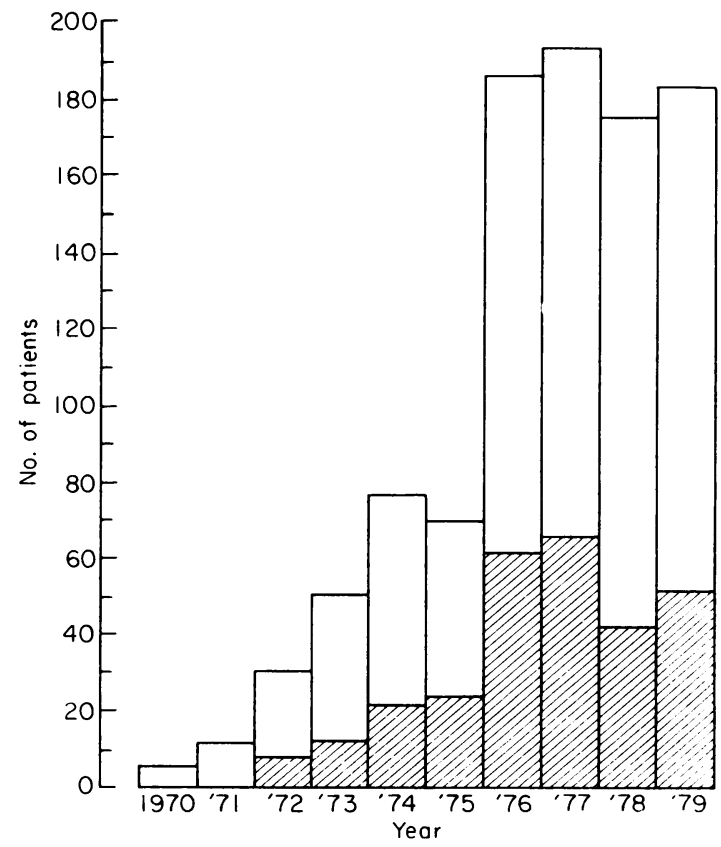

Fig. 1. Patients with malaria admitted to Birmingham Hospitals $1970-1979$. $\square$, all ages; $\mathscr{\mathscr { V }}$, children $\leqslant 16$ years. 
for between 8 and 21 days. One had had symptoms for one month, one for 2 months, one for 9 months and one for a year. Cyclical fever was reported in 19 patients. The duration of the cycle reported by the parents was $24 \mathrm{hr}$ in 7 patients, $48 \mathrm{hr}$ in 10 and $72 \mathrm{hr}$ in 2 . Fever, vomiting and rigors were the most common symptoms. Less frequent symptoms included abdominal pain (4 patients), headache (4), epistaxis (2), pallor, cough, limb pains and convulsions (one each). Examination revealed splenomegaly in 26 of the 32 patients. The only other frequent abnormality was pallor (9).

Anaemia was common (Fig. 2). Eight children had platelet counts performed and 6 had counts below $150 \times 10^{9} / 1$. The 2 children presenting with epistaxis had platelet counts of 35 and $101 \times$ $10^{9} / 1$. Four children had reticulocyte counts measured. Their haemoglobins were 7.7, 6.6, 7.8 and $6.6 \mathrm{~g} / \mathrm{dl}$ and reticulocyte counts were $13 \%, 5 \%$, $17 \%$ and $15 \%$. All the parasites were Plasmodium vivax.

A clinical diagnosis of malaria before laboratory confirmation was made in hospital in 21 of the 32 children. Only 3 children were referred by the general practitioner with the correct diagnosis although 24 had been seen by a general practitioner before admission. There is evidence, however, that many general practitioners may reach a correct diagnosis, have it confirmed in the hospital laboratory, and then treat the disease without referring the patient for admission, so the present data cannot be interpreted as showing that hospital doctors are any more or less likely than general practitioners tơ reach a correct clinical diagnosis. The most com $\frac{\varrho}{c}$ monly suggested wrong diagnosis leading to ad mission was urinary tract infection.

\section{Congenital infection}

A boy weighing $3.280 \mathrm{~kg}$ at term was born in this hospital. The mother had emigrated from India months previously. She had stopped taking antion malarial prophylaxis immediately after arrival and? began to experience intermittent fever one month $\vec{P}$ later.

The infant suffered from neonatal jaundice with maximum serum bilirubin of $251 \mu \mathrm{mol} / 1$ at the agg of 5 days but was otherwise well neonatally. There was no feto-maternal blood group incompatibility'

At the age of 6 weeks the infant was noticed to be pale on routine clinic attendance but there were no symptoms. The spleen was just palpable. The $\mathrm{Hbi}^{-}$ was $4.8 \mathrm{~g} / \mathrm{dl}$ and $P$. vivax was seen in the blood film. Treatment with chloroquine was curative.

\section{Discussion}

The incidence of malaria in the U.K. increase during the 1970s. The total number of cases of als ages reported to the Malaria Reference Laboratory was 662 in 1974, 1527 in 1977 and 2053 in 1989 Children of 12 years and under numbered 214 1 1977,222 in 1978 and 235 in 1979. These figures a⿳亠丷⿵冂丶 those now presented of hospital admissions ?trp Birmingham are undoubtedly underestimates of the number of malarial infections occurring in childrem
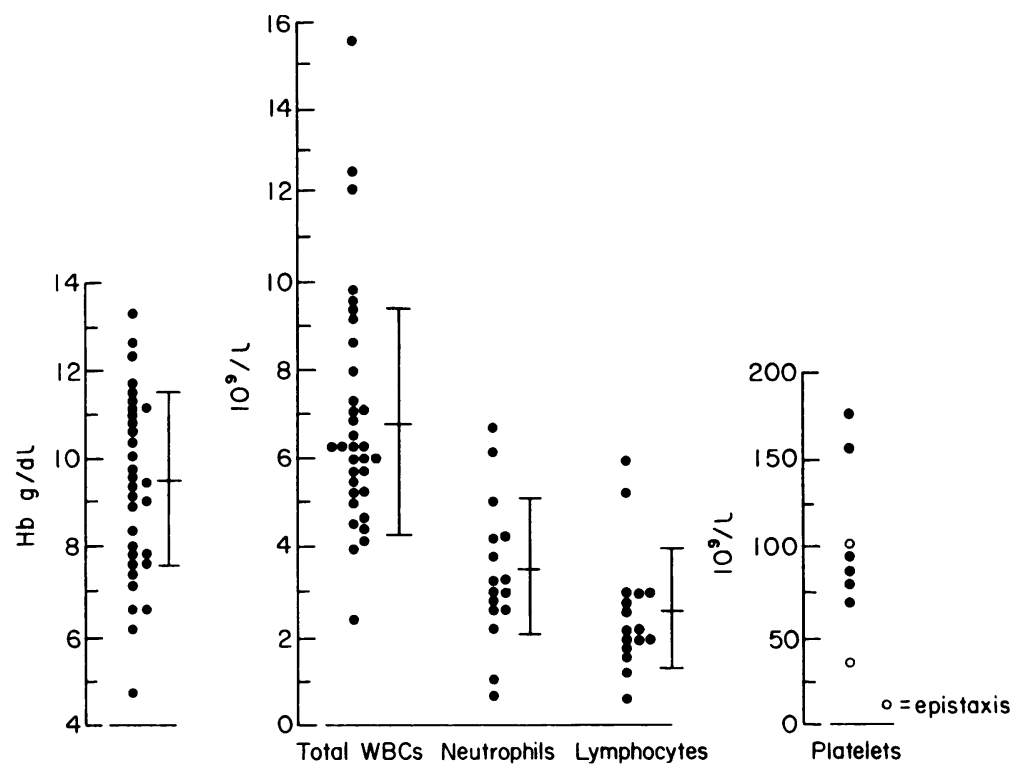

FIG, 2, Blood counts in 32 children with malaria. 
in the U.K. since not all infections are notified to the Malaria Reference Laboratory and general practitioners often refer patients to the hospital laboratory for diagnosis who are never seen again at the hospital. Of the 235 infections notified last year, 155 were acquired in India, 17 in Pakistan, 53 in Africa, 7 elsewhere and 3 transplacentally. Infections acquired in India and Pakistan, have so far almost invariably, been caused by $P$. vivax. Only one child with $P$. falciparum infection from India and one from Pakistan have been notified in the years 1977-79, but there is an appreciable amount of $P$. falciparum infection in the Indian sub-continent (Ellis et al., 1979).

Of the children in this series, $75 \%$ were born in this country and acquired the disease on visits to their parents' country of birth. It seems likely that the increased incidence of malaria in the U.K. in recent years reflects an increase in the number of Asian families paying visits to their countries of origin as well as the persistence (Communicable Disease Surveillance Centre, 1980) and, in some cases, increase of malaria in endemic areas (Dutta and Dutt, 1978).

Although $P$. vivax infection is not usually fatal it is a cause of considerable and avoidable morbidity. Attempts to educate travellers to endemic zones to take anti-malarial prophylaxis have not so far been conspicuously successful since it appears that many people either take no prophylaxis or stop taking it immediately on return to this country instead of continuing for one month. Since many travellers may not consult their general practitioners before leaving, the problem may not be solved by approaches through general practitioners. Educational approaches through immigrant organizations and the provision of information about prophylaxis along with air tickets to endemic areas would seem to be more appropriate (Kustner, 1979).

Congenital malarial infection does occur (Hall, 1978; Bradbury, 1977; Talib et al., 1978) and should be considered in any newborn infant with unexplained fever or anaemia whose mother has recently returned from an endemic area.

\section{Acknowledgment}

We thank Mr J. Simms for his help in the collection of these data.

\section{References}

Bradbury, A.J. (1977) Congenital malaria on one nonidentical twin. British Medical Journal, 2, 613.

Communicable Disease Surveillance Centre, Public Health Laboratory Service, Colindale (1980) Malaria in Britain 1979. British Medical Journal, 2, 624.

DutTA, H.M. \& DutT, A.K. (1978) Malarial ecology: a global perspective. Social Science and Medicine, 12, 69.

Ellis, C.J., Eykyn, S.J., Watkins, P., Bell, M. \& Geddes, A.M. (1979) Malaria in Birmingham and a London teaching hospital. British Medical Journal, 1, 385.

Hall, A.P. (1978) Preventing deaths from malaria. British Medical Journal, 2, 877.

KUSTNER, H.G.V. (1979) Trends in four major communicable diseases. South African Medical Journal, 55, 460.

Robinson, M.J. \& EYKYN, S. (1977) Childhood malaria in Britain. British Medical Journal, 2, 1667.

RutTer, N. (1977) Malaria in Nottingham children. British Medical Journal, 2, 1335.

Talib, V.H., Kiran, P.C., Nasreen, J.T. \& Choudhury, M. (1978) Plasmodium vivax malaria in the neonatal period. Indian Journal of Paediatrics, 45, 337.

Thompson, R.G., Harper, I.A., Patel, A.M. \& Allan, S.W.A. (1979) Malaria in Wolverhampton. British Medical Journal, 1, 952.

WARWICK, R., Swimer, G. \& BrITt, R. (1979) Increasing incidence of malaria in Britain. Lancet, i, 1242. 